\title{
Comparative Study on the Choice of Muslim Migrants Residence in Xi'an and Lanzhou Cities, China
}

\author{
Xiang Gao ${ }^{1}$, Xiaohua $\mathrm{Ma}^{1}$, Ke Wang ${ }^{1}$, Pingting Huang ${ }^{1}$, Xiaoting $\mathrm{Mi}^{1}$, Kuanmei Liu ${ }^{1}$ \\ ${ }^{1}$ Lanzhou University, China \\ Correspondence: Xiang Gao, Lanzhou University, China.
}

Received: September 29, 2019

Accepted: October 21, $2019 \quad$ Available online: October 25, 2019

doi:10.11114/ijsss.v7i6.4583

URL: https://doi.org/10.11114/ijsss.v7i6.4583

\begin{abstract}
Residential choice is one of the basic contents of urban adaptation of the floating population and an important aspect in determining the quality of life in the city. This study is for Muslim migrants with three attributes (minority, floating population and religious belief). The purpose is to reveal the commonalities and differences in the choice of living spaces of Muslim Migrants in multi-ethnic cities Lanzhou and Xi' an, to provide guidance for the targeted management of Muslim migrants and promote their urban integration. Based on available research data from 2017-2019, the study adopts spatial analysis and regression analysis to explore the results of the selection of Muslim migrants living space in two cities and its influencing factors. The main conclusions are as follows: 1) The commonality of Muslim migrants living space in the two cities lies in: the distribution pattern of "Living around the mosque and running business nearby the mosque" still exists. The living space of Muslim migrants consists of points (mosques), lines (streets or traffic lines), and faces (inhabited areas), forming a spatial distribution pattern of the "mosque + community" residential circle. Differences: Muslim migrants in Hui's street, Xi'an, taking the "Mosque-alley system" as an independent social organization, and their living space presents a " mosque-alley Interlaced" distribution. Muslim migrants living in the urban village community on the periphery of Hui's street take "mosque" and "farm market" as the dual core, showing the "core (mosque/market) + community" inlaid living space situation. The Muslim migrants in Lanzhou generally live around the mosque or close to the streets and roads that lead to mosque. 2). In terms of commonality, the living choices of Muslim migrants in both cities consider the distance from the place of work, the mosque or the Muslim community to the place of residence. In terms of differences, the residential choice of Muslim migrants in Xi' an is mainly influenced by the composition of the living, the income of wages, and the nature of the occupation. The choice is mainly influenced by the rent level, occupational nature and wage income of the house; and the main influencing factors of the choice of Muslim migrants in Lanzhou are the education level and the rent level of the house. The main influencing factors of residential location selection are education level and mobility purpose. The level of education, traditional living customs, and rent levels have become the core factors determining the urban accommodation adaptation of Muslim migrants.
\end{abstract}

Keywords: Muslim migrants, residential choice, impact factors, regression analysis, Lanzhou, Xi'an

\section{Introduction}

In the process of rapid urban development, residential space as a carrier of floating population living and social interaction has received more and more attention from the academic community (Wu et al,2010). Since the 1920s, Western scholars' research on living space gradually becomes systematic and perfect, a series of schools and research perspectives have been formed. Early life cycle theory has had an important impact on residential mobility and housing choices. Life course perspectives focus more on changes in social contexts, such as regional economic development, housing markets, and housing policies (Dieleman \& Mulder, 2002). The process of lifetime is accompanied by the movement of residence and the choice of residential location. It is also affected by changes in family, work economy income, and housing market reforms (Le, 2008; Smith \& Olaru, 2013). In terms of lifestyle perspective, the choice of residence can be understood as a certain lifestyle preference to a certain extent. Jian Ge et al. (2006) used the questionnaire data of two cities in Japan to analyze the influencing factors of residential choice and the characteristics of residential satisfaction and their relationship. Different lifestyle or residential preferences determine the difference in living choices (Thorkild Ær $\oslash, 2006$ ), people tend to choose to live in a homogeneous community. In terms of internal and external factors, the factors affecting urban residential location include individual factors (gender, ethnicity, etc.), external factors (commuting costs, relocation costs, 
safety and health, etc.). For example, Asiyanbola (2006) explored the participation of female residents in Ibadan, Nigeria, in decision-making on residential location through analysis of variance, correlation and simple statistics, and found that generally there was low involvement of women in residential location/ relocation decision-making. Prashker et al. (2008) explored the impact of commuting on the choice of residence in Tel Aviv, Israel, and thought that the important of both the area characteristics and the commute distance in choosing residential location and significant differences between men and women.

Domestic scholars' research on urban living space is in the ascendant stage of exploration. The research content mainly focuses on urban residential space selection and its influencing factors, living space differentiation and formation mechanism. A lot of research shows that in the floating population, there are certain regularities in the choice of residential location and the way of living (PRC. National Health Commission, 2019). The main residence methods include rented houses, collective dormitories provided by employers, and self-purchased commercial houses. Among them, renting houses is the main way of living for the floating population (Ding Jinhong et al., 2005; Mao Fengfu, 2009; Liu Tingting et al., 2014). For the choice of residential location, most people choose to live in urban or suburban areas. Some have lowered their requirements for quality of living to reduce their living costs (Lin Liyue, Zhu Yu, 2008), and these people tend to choose urban fringe areas or urban village communities and relatively concentrated places (Wang Guixin, 2005; Fu Lei, Tang Zilai, 2008). Different types of floating population living areas and their spatial structures are the result and manifestation of the living space selection behavior of the floating population. The microscopic living space selection behavior determines the macroscopic living space model (Tang Bo, 2013). Different patterns of living space distribution are the performance of multiple factors under the combined effect, but there are differences in the way of exerting influences, such as the choice of living space is affected by personal experience, the assets of the outflowing land and the social integration of the inflowing land (Liu Tao et al., 2019). The distribution of living space is determined according to the purpose of inflow and its own economic factors (Tian Jingfeng, Li Wenlong, 2018); housing choice is affected by factors such as housing affordability, average family education, and the number of people moving (Shi Zhilei et al., 2014).The economic factors for the choice of living space in Beijing's mobile population are far greater than the personal factors (Hou Jiawei, 2010). The discovery of low-cost housing sources will attract a large concentration of floating population (Yuan Yuan et al., 2007). Employment opportunities are the primary choice for living space of migrants. Influencing factors (Zhang Fei et al., 2010; Ren Yuan, 2012), residential area, rent, etc. have a significant impact on the living choice of the floating population (Zhang et al., 2018).

Compared with the general floating population, the floating population of ethnic minorities is a floating population of three-dimensional space in culture, time and geography (Xiu Wenyu, 2015). The Muslim migrants with the triple identity (floating population, ethnic minorities and Islam) have special living preferences. The distribution of mosques has potential appeal to the choice of living space of Muslim groups. In the city, the geographical structure transformed from "living around the mosque" to "living near the mosque" ( Zhang \& Yang, 2013). Under the tradition of "living around the mosque", "gathering" is the main form of living for Muslim migrants in Lanzhou. (Liao Hehe et al., 2016). For the economically developed regions such as Beijing, Shanghai, Guangzhou, and Nanjing, Muslim migrants live in the urban village community with enough housing and low rents based on "geography, ethnicity, or bloodline". The community is an important support for Muslim migrants to adapt and develop in the city. From the traditional living mode of "surrounding the temple" in the geographical space to the modern living mode of "living around the mosque", the Muslim migrants gradually merge into the city from the initial adaptation (Sha Yanfen, 2017). The factors influencing the choice of residence are also diverse (Liu Zhicai et al., 2009; Li Wubin, 2015).

There are about 20 million Muslims in 10 ethnic minorities in China, and 3 million inflows into the city (Jin \&Qiu, 2009). The change in the size of the floating population indicates that China's population migration is entering a new stage. The increase of urban Muslim migrants has brought certain challenges to urban social management, public services and ethnic relations (Gao\&Cao, 2012). Xi' an and Lanzhou City are two large-scale multi-ethnic cities in the vicinity of the city, the urban adaptation of Muslim migrants in these two cities is representative. By judging the commonalities and differences of Muslim migrants' choices, it provides targeted management guide and promotes the integration of Muslim migrants into the city.

\section{Materials and Method}

\subsection{Time and Space Range}

\subsubsection{Scope of Research}

Lanzhou, the capital of Gansu Province, lies between $102.24^{\circ} \sim 104.33^{\circ} \mathrm{E}$ and $35.23^{\circ} \sim 37.42^{\circ} \mathrm{N}$, Northwest Territories, an important industrial base and integrated transportation hub, one of the important central cities in the western region, an important node city in the Silk Road Economic Belt. There are 5 municipal districts under the jurisdiction of Chengguan, Qilihe, Xigu, Anning and Honggu, and 3 counties under the jurisdiction of Yongdeng, Gaolan and Yuzhong. At the end of 
2018, the city's permanent resident population was 3,753,600, and the floating population was 660,000 , of which 47,000 were Muslims (Lanzhou Floating Population Management Brigade). Now there are more than 30 ethnic groups including Han, Hui, Tibetan, Dongxiang, Yugu and Sala. There are 66 religious sites such as mosque and Gongbei, mainly distributed in Chengguan District and Qilihe District (Islamic Islamic Association), and the floating population there is about 90,000-100,000 including 10 ethnic minorities (Hui, Dongxiang, Uygur, Sala, Baoan, Kazakh, Kirgiz, Tajik, Tatar and Uzbekistan).

According to the actual distribution of the Muslims Living for generations and Muslim migrants in Lanzhou City, combined with the distribution of religious places such as mosques and the pre-investigation of the areas where Muslim migrants lived in the past, Lanzhou research mainly concentrated in specific areas of the four districts of the main city. Specifically, it includes Baiyin Road, Zhangye Road and Railway Station Street in Chengguan District; Xiyuan Street and Xihu Street in Qilihe District are the main areas, among which the most concentrated areas of Xihu Street are Camel Lane, Jian'gouyan Road, and Xiyuan Street are concentrated. There are Baishu Alley, Shangxiyuan Road and Xiaxiyuan Road; Peili Square and Taohai Market in Anning District; Xianfeng Road, Fuli Road and Lintao Street in Xigu District (Figure 1).

Xi' an, the capital of Shaanxi Province, lies between $107.40^{\circ} \sim 109.49^{\circ} \mathrm{E}$ and $33.42^{\circ} \sim 34.45^{\circ} \mathrm{N}$. It belongs to the economic, cultural and commercial center of the Silk Road Economic Belt. It is an important central city in the western part of China approved by the State Council, and the largest city in the Yellow River Basin. It has jurisdiction over 11 districts including Weiyang District, Xincheng District, Beilin District, Lianhu District, Baqiao District, Yanta District, Yanling District, Lintong District, Chang'an District, Gaoling District and Huyi District, and 2 counties of Lantian and Zhouzhi. At the end of 2018, the resident population of Xi'an was 1,003,700. There are 52 ethnic minorities, of which Hui people have the largest population, with 64,200 people, accounting for $75.28 \%$ of the total minority population. The area with the largest ethnic minority population is Lianhu District, with a population of 35,000, of which the number of Hui people is 32,000.

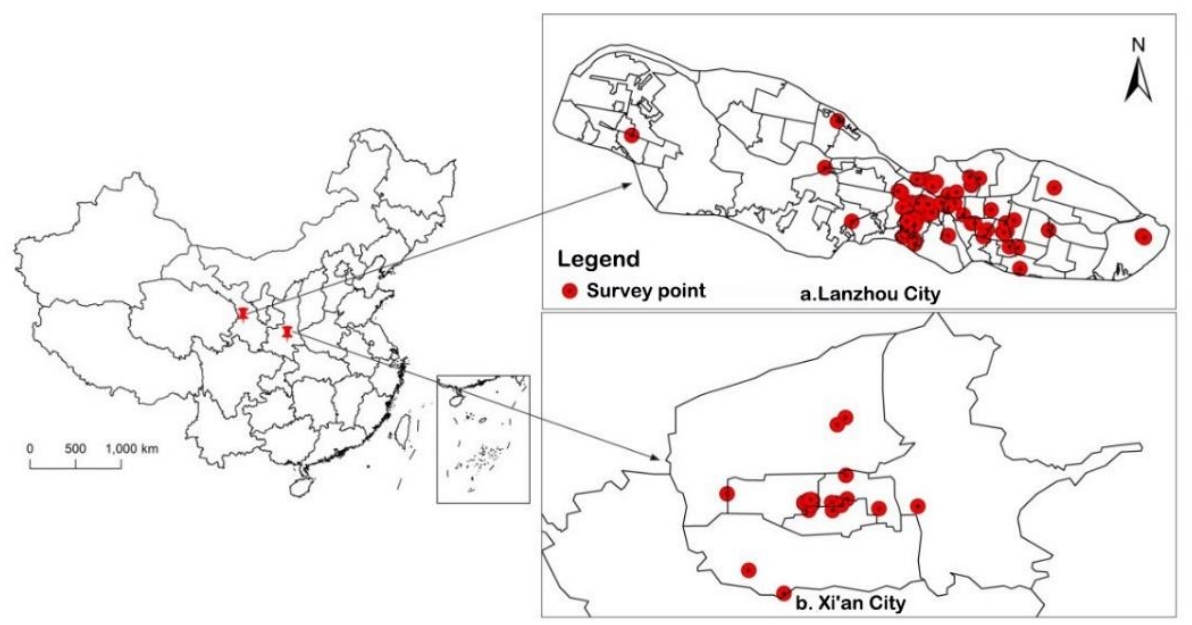

Figure 1. Schematic diagram of the distribution of urban Muslim migrants survey points

The distribution density of the floating population in the city is larger in Xincheng District, Lianhu District and Beilin District. The Lianhu District is a typical gathering area for Muslims (Figure 1).

There are 13 mosques of different sizes in the Huifang. The "Huifang" is actually a collective name for many streets in Hui's block. It consists of several streets including Beiyuanmen, Xiyangshi, Huajue Lane, Dapiyuan, Guangji Street and Sajinqiao, and forming different numbers of settlements in different streets. Among them, the Beiyuanmen is the main street, and each street is about 500-800 meters in length. The residents and Muslim migrants in the area are engaged in the tertiary industry, such as saling handicraft, operating halal restaurants and processing ethnic foods. Huifang has become an important commercial economic node that drives the income growth of residents (including Muslim migrants).

\subsubsection{Time Definition}

The object of this study - Muslim migrants, has been living in Lanzhou for more than 3 months, mainly from rural areas, towns and counties across the county-level administrative divisions into Lanzhou City, does not change the household registration. They earn a certain income through various economic activities and they are Minority floating population affected by Islamic culture. During the three-year span from 2017 to 2019, on the one hand, the multidimensional adaptation (environmental, economic, social) of respondents had been basically completed, on the other hand, their 
residential relocation information can be enough to get over the same period.

\subsubsection{Data Source}

The macro data of the two cities was obtained from the sixth census, the city yearbook and the monitoring data of the floating population. The sample data mainly comes from the questionnaire survey. The information acquisition methods include random questionnaires, semi-structured interviews, and in-depth interviews. On the one hand, taking mosques as a guide, and random interviews are conducted on halal dining restaurants along the street and ethnic food outlets. On the other hand, primary and secondary schools in the areas where Muslim migrants live in concentrated areas are assisted by the school to distribute the questionnaires to students. Parents were required to fill in because the school is a stakeholder, parents were willing to cooperate, and the questionnaire recovery effect was better. The members of the research team conducted field research in Lanzhou and Xi'an during the three periods from April to June 2017, March to June 2018 and May to August 2019. The researchers distributed 700 questionnaires in Xi'an and Lanzhou respectively, and finally collected 631 and 673 valid questionnaires, with effective rates of $90.1 \%$ and $96.1 \%$, respectively.

\subsection{Research Methods}

Factor analysis (SPSS) converts multiple observed variables into a few unrelated comprehensive indicators according to the size of the correlation in multivariate statistics, so that the variables in the same group are highly correlated, and the variable correlations in different groups. Each set of variables represents a structure that becomes a common factor (Hao et al, 2018). The factor load represents the correlation coefficient between the variable and the main factor. The larger the load, the larger the correlation coefficient is, and the closer the relationship between the variable and the main factor. The factor variable and the original variable are obtained by analyzing the factor load matrix. The relationship between the new factor variables can be represented by a mathematical model:

$$
\begin{gathered}
x_{1}=a_{11} F_{1}+a_{12} F_{2}+\cdots+\cdots a_{1 m} F_{m} \\
x_{2}=a_{21} F_{1}+a_{22} F_{2}+\cdots+\cdots a_{2 m} F_{m} \\
\cdots \\
x_{p}=a_{p 1} F_{1}+a_{p 2} F_{2}+\cdots+\cdots a_{p m} F_{m}
\end{gathered}
$$

Where $\mathrm{x} 1, \mathrm{x} 2, \ldots, \mathrm{xp}$ are $\mathrm{p}$ original variables, which are normalized variables with a mean of 0 and a standard deviation of $1, \mathrm{~F} 1, \mathrm{~F} 2, \ldots, \mathrm{Fm}$ is $\mathrm{m}$ factor variables, $\mathrm{m}$ is less than $\mathrm{p}$, expressed in a matrix form:

$$
X=A F+a
$$

Where $\mathrm{F}$ is a common factor and $\mathrm{A}$ is the factor load matrix, which is the load of the $\mathrm{i}$-th original variable on the $\mathrm{j}$-th factor variable.

\section{Muslim Migrants Residence Selection Results}

The Muslim migrants in Lanzhou have a gender structure of "more men and fewer women", which possessed an important relationship with the gender roles of the local society. The values of "man is responsible for making money outside and women should take care of the family" limits the behavior of women going out to work. Besides, the gender choice of urban economic development for migrant Muslims also affects the scale of mobility (Zhang, 2012). Xi'an City presents a "balanced gender structure" of Muslim migrants; the overall age structure is "young", mainly for people aged 21-40, followed by 40-50 age group. The proportion of over-50-year-old people is very low, which is the same as the age distribution of the main rural labor force. In terms of education level, Lanzhou Muslim migrants are concentrated between illiterate and primary, primary and junior high schools, while migrant Muslims in Xi'an are between primary schools and between junior high schools; the marital status of the surveyed Muslim migrants in the two cities basically tended to be the same, and the married groups accounted for $94.2 \%$ (Xi'an) and 86\% (Lanzhou) respectively.

\subsection{Residential Structure}

The residential structure involves the living style, residential composition, the cost of living, the living area, and the time limit for residence. Due to low income and instability, urban Muslim migrants mainly take rental housing as their main choice. The proportion of Muslim migrant renters in Xi' an and Lanzhou is far more than half, accounting for $96.5 \%$ and $75.2 \%$ respectively. Muslim migrants generally enter the city to find a place to settle through the geographical, ethnic and kinship traditional social relations. One end of the "social chain of acquaintances" refers to ethnic minority migrants who have no experience in urban life, and the other end is relatives or friends who have lived in the city. The latter, because it already has a certain city life experience, can provide various help to the former to ease the uneasiness and strangeness after entering the city. The listings are generally concentrated in communities near the mosque and in 
lower-priced neighborhoods. The structure of Muslim migrants in Xi' an and Lanzhou is more obvious. The mobility of family members has become a trend. Couples living together or living with their children can work and do business on the one hand and get high-quality education opportunities for their children on the other hand. From the monthly housing rent level, Lanzhou City is concentrated between 201-600 yuan, and Xi'an City is concentrated between 601-800 yuan. The rent level determines the living environment and quality. In terms of length of residence, the Muslim migrants in Lanzhou City are mainly inter-city flows in the province, and the average residence time is mainly 2-5 years. Most of the Muslim migrants in Xi' an belong to inter-provincial flows, and the long-distance migrants' residence time is relatively long., concentrated in two periods of 2-5 years and 6-10 years (Table 1).

Table 1. Muslim migrants living structure

\begin{tabular}{|c|c|c|c|c|c|}
\hline \multirow{2}{*}{ Attribute } & \multirow{2}{*}{ Category } & \multicolumn{2}{|c|}{ Lanzhou } & \multicolumn{2}{|c|}{ Xi'an } \\
\hline & & Sample Size & Proportion & Sample Size & Proportion \\
\hline \multirow{3}{*}{ Housing nature } & Rent a private house & 557 & 82.8 & 615 & 97.5 \\
\hline & Purchased house & 76 & 11.3 & 13 & 2.1 \\
\hline & Place of employment & 40 & 5.9 & 3 & 0.4 \\
\hline \multirow{8}{*}{ Living composition } & Unmarried & 17 & 2.5 & 13 & 2.1 \\
\hline & Unmarried and living with parents & 21 & 3.1 & 1 & 0.2 \\
\hline & Married alone & 38 & 5.6 & 2 & 0.3 \\
\hline & Husband and wife living together & 107 & 15.9 & 195 & 30.9 \\
\hline & Couples living with their children & 299 & 44.4 & 390 & 61.8 \\
\hline & Couple living with their parents & 29 & 4.3 & 4 & 0.6 \\
\hline & Living with three generations or more & 54 & 8.0 & 8 & 1.3 \\
\hline & Living with others & 108 & 16.0 & 18 & 2.9 \\
\hline \multirow{7}{*}{ House area $/ \mathrm{m}^{2}$} & More than 800 & 94 & 14.0 & 217 & 34.4 \\
\hline & Less than or equal to 10 & 42 & 6.2 & 7 & 1.1 \\
\hline & $11-20$ & 219 & 32.5 & 17 & 2.7 \\
\hline & $21-30$ & 123 & 18.3 & 299 & 47.4 \\
\hline & $31-50$ & 132 & 19.6 & 261 & 41.4 \\
\hline & $51-80$ & 93 & 13.8 & 31 & 4.9 \\
\hline & More than 80 & 64 & 9.5 & 16 & 2.5 \\
\hline \multirow{5}{*}{ Length of residence } & Less than or equal to 3 months & 111 & 16.5 & 3 & 0.5 \\
\hline & 4 months - 1 year & 182 & 27.0 & 20 & 3.2 \\
\hline & $2-5$ years & 205 & 30.5 & 371 & 58.8 \\
\hline & $6-10$ years & 92 & 13.7 & 224 & 35.5 \\
\hline & More than 10 years & 83 & 12.3 & 13 & 2.1 \\
\hline
\end{tabular}

People with different characteristics also have different choices of living styles. From the perspective of gender, male and female Muslim migrants mainly rent houses in terms of choice of living methods, but in comparison, the proportion of male renters is higher than that of female renters and the proportion of males in Lanzhou who choose non-rental (employment places, etc.) is higher than that of Xi'an. The proportion of married couples in Xi'an and Lanzhou who choose to rent a house is significantly higher than that of unmarried groups. For migrants who are divorced (divorced or widowed), the proportion of rented houses in Lanzhou is much higher than that of non-rental houses. Muslim migrants in primary schools and below have the highest proportion of rented houses. Muslim migrants in the 20-30 age group are more inclined to rent a house in terms of their choice of living style. As the age group continues to increase, the proportion of rented houses is slightly reduced. From a professional perspective, Muslim migrants engaged in catering industry have the highest proportion of rented houses, followed by vendors. From the perspective of wage income, the monthly income of Muslim migrants in Xi'an is relatively high in the range of 2001-4000 yuan, while the monthly income of Muslim migrants in Lanzhou is higher in the range of 1001-3000 yuan. From the perspective of residential location, Muslim migrants in Xi'an choose to rent in the urban area. The urban population has a large flow of people, and there are many employment opportunities and help to increase wage income. The Muslim migrants in Lanzhou has the highest proportion of renting houses in the far suburbs.

\subsection{Residential Pattern}

The choice of living places for Muslim migrants is mainly related to occupation, means of transportation and mobility purposes. Xi'an has many employment opportunities people. The number of migrants who work in the national catering industry choose to live in the urban area, followed by vendors, accounting for $24.6 \%$. The situation in Lanzhou City and $\mathrm{Xi}$ 'an City is slightly different. The choice of ethnic catering and traders is mostly in the suburbs. On the one hand, there is a direct relationship with the rent of houses. The rental rent in the downtown area is generally higher than that in the suburbs. Convenience and low housing rents are the main location choices for Muslim migrants. From the perspective of 
transportation methods and mobility purposes, Muslim migrants with the main purpose of running business often choose urban areas with more employment opportunities. Some of the Muslim migrants in Lanzhou belong to the same flow. If the husband and wife carry their children, they choose urban residents because of their children's education problems, but the overall preference is low living cost areas (Table 2).

Table 2. Different characteristics of Muslim migrants' residential location selection (unit: \%)

\begin{tabular}{|c|c|c|c|c|c|c|c|}
\hline & \multicolumn{3}{|c|}{ Xi'an } & \multicolumn{3}{|c|}{ Lanzhou } \\
\hline & & Urban area & Near suburb & Far suburb & Urban area & Near suburb & Far suburb \\
\hline \multirow{4}{*}{ Occupation } & Vendor & 24.6 & 6.7 & 4.1 & 15.1 & 31.6 & 28.8 \\
\hline & Ethnic dining & 51.3 & 4.0 & 8.6 & 42.1 & 56.6 & 32.4 \\
\hline & Transport & 0.2 & 0.0 & 0.0 & 3.9 & 0.0 & 5.2 \\
\hline & other & 0.6 & 0.0 & 0.0 & 38.8 & 11.8 & 33.7 \\
\hline \multirow{2}{*}{ Transportation } & Walk & 76.1 & 10.5 & 12.7 & 48.7 & 64.5 & 56.6 \\
\hline & Bicycle & 0.6 & 0.2 & 0.0 & 51.3 & 35.5 & 43.4 \\
\hline \multirow{2}{*}{ Flow purpose } & $\begin{array}{l}\text { Work or do } \\
\text { business }\end{array}$ & 76.7 & 10.5 & 12.7 & 65.8 & 81.6 & 82.9 \\
\hline & other & 0.0 & 0.2 & 0.0 & 34.2 & 18.4 & 17.4 \\
\hline
\end{tabular}

As the basis and important component of urban spatial structure, living space generally refers to the material form of residential areas of different social groups and the social relationship reflected by this material form. This spatial external manifestation is geospatial, and its internal essence is the social space that contains the relationship (Shen, 2008). Wu Xiao (2010) proposed that the distribution of living space of floating population in large cities in China presents two main forms: urban villages and urban settlements. On the macro level, the Muslim migrants' residential areas can be divided into main urban areas, suburban areas and remote suburbs. However, considering the special living choices and directions of Muslim migrants, the specific residential space pattern is also characterized. Field visit found that the Muslim migrants in Xi'an and Lanzhou had both commonalities and local differences in the distribution of living space. The commonality lies in the fact that the distribution of mosques in the place has a potential guiding effect on the choice of Muslim migrants. The Muslim migrants in the same way as the Muslims in the city have basically formed the spatial pattern of "living around the mosques". The difference is that the Muslim migrants in Xi'an present a spatial distribution based on the mosques living in the square and the surrounding businesses. Huifang is a region with unique national culture and ethnic customs in Xi'an. Huifang has formed a national catering business, tourism gathering circle, a small-scale reproducible industry, many job opportunities, and promoted and attracted Muslim migrants as a foothold, around the square has formed a residential employment model around the development of the business circle. The typical "square-style" static living space in Xi' an is composed of social, spatial and cultural elements. The interaction between them forms a stable spatial structure based on the "Mosque-alley system" pattern (Hua, 2011). The Muslim Mosque in Huifang lives in different communities and is mainly within 300 meters of the mosque. The Muslim migrants in Lanzhou City shows a fan-shaped living space spread with the mosque as the core and relying on the mainline of transportation, such as the Xiaoxihu and Shangxiyuan as the core settlement area and the scattered residence along the industrial road and the trench along the main road. The mobile Hui merchants have a spatial dependence on the structure of the "Mosque-alley system" (Ai Shaowei, 2017). The distribution of the mosque has a potential guiding effect on the Muslim migrants entering the city. When Muslim migrants choose living space, in addition to the mosque, the conditions of the supporting service institutions in the region are also important aspects to consider. Different living spaces choose different living circles. The living circle refers to a circular activity range formed in the city, or a small area of the city, shopping, business, life, school, medical care, cultural activities, etc. (Tan, 2013). The survey found that migrants in Xi'an and Lanzhou form a 15-25-minute residential life circle with a mosque as the core. The circle market, business center, school, bank, and hospital service institutions are relatively complete, which can meet the basic needs of Muslim migrants. Muslim migrants in the two cities is mainly on foot, supplemented by bicycles and buses. According to the general step frequency and stride, and according to the basic service institutions covered by walking time and walking distance, it is possible to roughly determine the living circle of Muslim migrants around the mosque for four years. For example, the mosque in Huajuexiang, Xi' an City is the center of life, extending the 15-25-minute residential life circle, living around the mosque, and running business with the streets. The 15-25-minute residential life circle formed by the Lanzhou Xiaoxihu Mosque is the center. However, there are differences in the spatial distribution patterns of service organizations in the living circles of the two cities (Figure 2). 


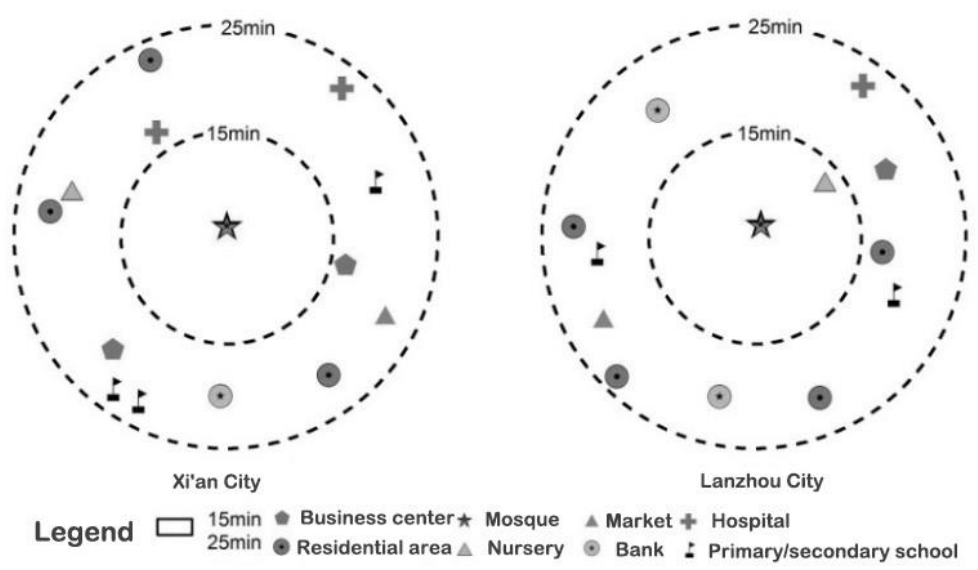

Figure 2. the living circle of Muslim migrants around the mosque

In addition to the mosque-centered circle living pattern, the living of Muslims in the two cities also presents a relatively concentrated situation of urban villages. The urban village has the dual attributes of urban and rural areas, belongs to the product of the rapid process of urbanization. It is a special area in the city, a special active area formed by the population of different social strata and different sources. The investigation found that Xi' an Huimin New Village, Nanhe New Village, Shanbei Village and Heyuan New Village belonged to the urban village community and gathered the floating population mainly engaged in the national catering industry and ethnic characteristic products. The source of Muslim migrants in the same urban village community is very similar. According to the questionnaire data, $80 \%$ of the Muslim migrants in Huimin New Village are from Henan, and 70\% of Nanhe New Village are from Tianshui, Pingliang and Linxia in Gansu, the same or similar sources of origin have formed a Muslim migrants agglomeration community. Many rental houses in urban village provide Muslim migrants with accommodations that are compatible with their economic income and gradually integrate into the nearby mosque Jamaat community (Yang, 2001). The Muslim migrants living space in urban village of Xi'an is a relatively concentrated living area around the "Dongcheng Mosque". The "farm market" about 200 meters from the mosque is their main employment area. Most of them are mobile or semi-fixed vendors, who are distributed on Yongle Road, Enamel South Lane, Zhongxing Road and Beiguomen. They mainly rely on Metro Line 1 to establish contact with other areas. Huimin New Village mainly consists of Muslims from Henan and Gansu provinces. There are more self-built houses, housing is crowded, and the environment is poor. Lanzhou Xiaoxihu, Shangxiyuan, Baishu Alley and other areas have also formed settlements of urban villages of different scales. At present, the Xiaoxihu area is a concentrated area where Muslim migrants live and work in Lanzhou. The Muslim migrants mainly come from Linxia, Guanghe, Kangle, Tianshui and Pingliang in Gansu Province, mainly Hui and Dongxiang. Close to the mosque, rented in the same community based on "geography or ethnicity". Compared with other regions, the Xiaoxihu area is not only available for renting, but also has a high density of Muslims, and more attractive to foreign Muslims. At the same time, there are many ethnic restaurants, large-scale ethnic souvenirs, sales markets and ethnic food manufacturing and processing enterprises in the Xiaoxihu area. This also attracts Muslim migrants to choose their own jobs on a large scale.

\section{Factors Affecting of the Choice of Muslim Migrants Residence}

Taking the mode of residence, living area, and residential location as dependent variables, the personal factors of Muslim migrants (age, gender, marital status, education level), housing factors (residence duration, family composition, rent rent), employment factors (occupation, wages, transportation methods) and flow factors (flow purpose, flow range, changes in the pattern around the mosque) are independent variables. Through multiple logit regression analysis of the living patterns and living location choices of Muslim migrants, the living area of Muslim migrants is selected. Multivariate linear regression analysis was carried out to compare and analyze the influencing factors of the choice of Muslim migrants living space in two cities.

\subsection{Influencing Factors of Residential Location Selection}

Using the residential location of Muslim migrants as the dependent variable, gender, age, ethnicity and marital status as the control variables, the professional nature, education level, salary and income, flow range, flow purpose, residential structure, monthly rent, transportation method, the impact on the choice of residential location. Taking the suburbs as a reference group, the regression results are shown in Table 3. The regression coefficients and standard errors reported, and the insignificant independent variables are not included. 
Table 3. Multiple Logit regression results for Muslim migrants' residential location selection

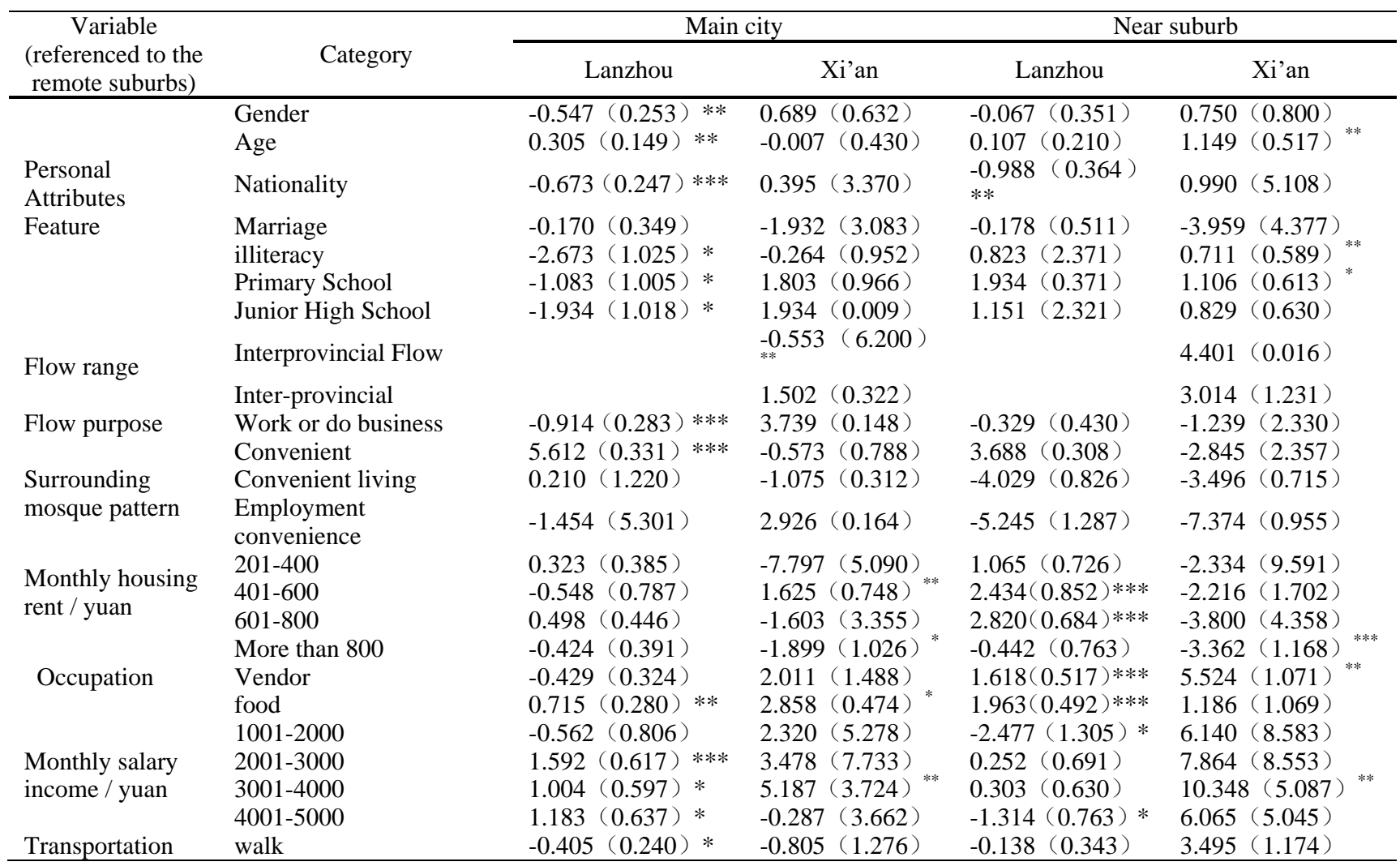

Note. The regression coefficient and standard error are listed in the table (the significance level $* * *$ represents $\mathrm{p}<0.001$, $* *$ represents $\mathrm{p}<0.05, *$ represents $\mathrm{p}<0.1)$.

It can be seen that there are significant differences in the factors affecting the choice of residential locations in Xi'an and Lanzhou. Xi'an is mainly affected by factors such as the scope of the flow, monthly housing rent, occupation, and wage income. Cross-provincial mobile wages with a wage income of 3001-4000 yuan, which are engaged in the national catering industry, choose to live and develop in urban areas. Occupation and self-employment income determine the relatively high quality of living, and the employment opportunities in the main urban area are far greater than those in the suburbs. The layout of basic living facilities is dense and balanced, and easy to use. Choosing to live in the suburbs has a significant correlation with age, education level and economic income. The Muslim migrants in the suburbs are mainly mobile traders. Their economic income is low and unstable. They do not have high requirements for social public services and the allocation of public facilities in residential areas. The low rent housing near the suburbs can meet their basic living needs. The choice of Muslim migrants in Lanzhou City is mainly influenced by education level, siege pattern, mobility purpose, occupation, etc. The degree of education is inversely related to the choice of residential location. The higher the education level of the respondents, the higher the requirements for the living environment and quality. The tradition of "living around mosques and running business near mosques" has a strong attraction for Muslim migrants to choose their places of residence. Due to the universalization of halal catering services, and the high density distribution of halal restaurants in the city, so in order to increase income and reduce commuting costs, these Muslim migrants also choose to live near a convenient mosque. Because of the low cost and high reproducibility of retailing and catering, most Muslim migrants make a living by selling and catering services. Muslim migrants with poor families usually choose to live in the suburbs, considering the cost of rent.

\subsection{Influencing Factors of Choice of Living Methods}

It analyzes the influence of mobile characteristics (flow range, mobility purpose), employment characteristics, residential characteristics and traffic conditions of Muslim migrants in two cities on their choice of living style. The dependent variable is the Muslim way of living, that is, the "housing nature" in the questionnaire, and multiple logit regression analysis is performed using the employment place as a reference group (Table 4). 
Table 4. Multiple Logit regression results for Muslim migrants' choice of living patterns

\begin{tabular}{|c|c|c|c|c|c|}
\hline \multirow{2}{*}{$\begin{array}{l}\text { Variable } \\
\text { (referenced to the } \\
\text { remote suburbs) }\end{array}$} & \multirow{2}{*}{ Category } & \multicolumn{2}{|c|}{ Main city } & \multicolumn{2}{|c|}{ Near suburb } \\
\hline & & Lanzhou & Xi'an & Lanzhou & Xi'an \\
\hline & Gender & $-0.149(0.307)$ & $-0.201(0.645)$ & $0.270(0.338)$ & $-.031(0.727)$ \\
\hline Personal & Age & $0.004(0.174)$ & $0.299(0.388)$ & $0.234(0.185)$ & $0.335(0.428)$ \\
\hline Attributes & Nationality & $-0.333(0.290)$ & $1.247(1.260)$ & $-0.099(0.314)$ & $1.200(1.297)$ \\
\hline \multirow[t]{2}{*}{ Feature } & Marriage & $-0.236(0.457)$ & $-0.222(1.088)$ & $-0.012(0.473)$ & $-1.097 （ 1.736)$ \\
\hline & Education level & $0.545(0.170) * * *$ & $0.761(0.471)$ & $0.439(0.179) * *$ & $0.937(0.542)$ \\
\hline \multirow[t]{3}{*}{ Flow status } & Interprovincial Flow & $0.472(0.973)$ & $2.245(1.367)^{*}$ & $0.375(0.969)$ & $1.074(1.813)$ \\
\hline & Work or do business & $-0.731(0.455)$ & $-1.523(2.538)$ & $-0.136(0.469)$ & $4.905(2.057)$ \\
\hline & Convenient & $-0.741(1.319)$ & $-0.573(0.788)$ & $1.120(1.276) * *$ & $-5.619(0.870)$ \\
\hline \multirow{3}{*}{$\begin{array}{l}\text { Surrounding } \\
\text { mosque pattern }\end{array}$} & Convenient living & $-0.694(1.319)$ & $-1.075(0.312)$ & $-0.191(1.362)$ & $-8.863(0.874)$ \\
\hline & $\begin{array}{l}\text { Employment } \\
\text { convenience }\end{array}$ & $-0.837(0.319)$ & $2.926(0.164)$ & $-0.244(0.002)$ & $-9.037(0.905)$ \\
\hline & $201-400$ & $-5.088(0.688) * * *$ & $6.343(3.104)^{* * *}$ & $0.775(0.576)$ & $1.245(1.596)$ \\
\hline \multirow{3}{*}{$\begin{array}{l}\text { Monthly housing } \\
\text { rent / yuan }\end{array}$} & $401-600$ & $0.841(0.875)$ & $0.535(0.929)^{* *}$ & $1.080(1.166)$ & $-0.708(1.089)$ \\
\hline & $601-800$ & $-0.224(0.484)$ & $-0.447(1.406)$ & $-0.084(0.781)$ & $0.132(1.598)$ \\
\hline & More than 800 & $0.983(0.499) * *$ & $-0.203(0.819)$ & $1.638(0.669)$ & $0.379(0.946)$ \\
\hline \multirow{4}{*}{ Occupation } & Vendor & $1.595(0.407) * * *$ & $0.803(2.238)$ & $-0.750(0.421) *$ & $-0.277(3.872)$ \\
\hline & food & $-0.545(0.392)$ & $0.717(2.258)^{* *}$ & $-1.021(0.421) *$ & $-0.203(3.879)$ \\
\hline & Transportation & $-0.553(0.795)$ & $7.467(16.733)$ & $-0.946(0.949)$ & $6.514(17.893)$ \\
\hline & $1001-2000$ & $2.150(1.122) *$ & $-1.294(1.960)$ & $0.058(1.163)$ & $-3.401(2.499)$ \\
\hline Monthly salary & $2001-3000$ & $0.991(0.640)$ & $-0.418(1.643)$ & $-0.539(0.686)$ & $3.174(1.189)$ \\
\hline \multirow{2}{*}{ income / yuan } & $3001-4000$ & $0.463(0.583)$ & $-0.164(1.589)$ & $-0.437(0.632)$ & $-1.476(1.679)$ \\
\hline & $4001-5000$ & $-0.115(0.610)$ & $0.644(2.305)$ & $-0.064(0.654)$ & $-0.059(2.429)$ \\
\hline \multirow[t]{4}{*}{ Transportation } & walk & $-0.586(0.300) *$ & $-1.808(9.416)$ & $-0.977(0.335) * *$ & $-7.890(9.351)$ \\
\hline & Unmarried & $1.234(1.066)$ & $1.482(1.364)$ & $0.721(1.131)$ & $2.388(2.323)$ \\
\hline & Live with their & $0.239(0.993)$ & $5.725(16.706)$ & $1.126(0.902)$ & $5.270(17.740)$ \\
\hline & Married and live alone & $-0.035(0.663)$ & $6.376(4.268)$ & $-0.562(0.809)$ & $-0.223(15.236)$ \\
\hline \multirow{4}{*}{$\begin{array}{l}\text { Live } \\
\text { Composition }\end{array}$} & $\begin{array}{l}\text { The couple living } \\
\text { together }\end{array}$ & $0.268(0.533)$ & $3.193(1.383)^{* *}$ & $-0.486(0.609)$ & $1.581(1.876)$ \\
\hline & Couple with children & $0.950(0.485) * *$ & $3.370(1.343)^{* *}$ & $0.372(0.542)$ & $1.966(1.813)$ \\
\hline & Couple and parents & $1.039(0.966)$ & $2.920(9.353)$ & $1.669(0.975) *$ & $-0.255(10.570)$ \\
\hline & $\begin{array}{l}\text { Three generations or } \\
\text { more }\end{array}$ & $0.783(0.721)$ & $0.960(2.606)$ & $1.434(0.647) * *$ & $-1.540(3.383)$ \\
\hline
\end{tabular}

Note. The regression coefficient and standard error are listed in the table (the significance level $* * *$ represents $\mathrm{p}<0.001$, $* *$ represents $\mathrm{p}<0.05, *$ represents $\mathrm{p}<0.1)$.

The Muslim migrants in Xi'an choose to rent houses as the main way of living. The inter-provincial flow for the purpose of running business is generally to rent private houses in the urban area and is significantly affected by the rent level. In order to save the cost of living, Muslim migrants engaged in the catering industry are more inclined to choose rental housing. In addition, family migration in rural-urban migrants has become a major trend. Families that husband and wife live together or with their children are more willing to choose urban rental housing, mainly for the convenience of their children. For the Muslim migrants who buy houses in the city or build their own homes, the main decisive factors are the wage income level and the city lifetime limit, and other factors have no significant impact on them. The choice of Muslim migrants in Lanzhou is mainly influenced by housing rent, occupation type, and transportation mode. Mobile traders tend to choose to rent private houses, and the rents they can afford are distributed at both ends of the rent range. This explains to some extent the polarization or uncertainty of the income of mobile traders. The "amphibious people" who flow to Lanzhou and often travel between the outflow and the inflows in the province also tend to choose rental housing. The choice of private rental housing is more significant than the usual walking mode, indicating that the Muslim migrants' workplace or mobile business district is not far from the place of residence, the traffic accessibility around the residence is relatively good, and the distance from the mosques of religious venues not too far. For Muslim migrants who have already purchased a house, they prefer housing sources with high employment convenience.

\section{Conclusion and Discussion}

1) The choice of living space for Muslim migrants is a trade-off between factors such as personal residence preferences, housing needs, and economic income. Renting housing is the main form of residence, and it is more inclined to urban Muslim colony areas with large employment opportunities and convenient transportation. There are also some suburban areas where low rents are selected to reduce the cost of living. Semi-fixed vendors are the main means of livelihood. Muslim migrants in Xi' an tend to choose houses with large living areas (mainly 21-30 and 31-50 square meters), and 
Lanzhou's Muslim migrants tend to choose houses between 11-20 and 21-30 square meters. As income levels increase, some Muslim migrants will choose to rent a house or purchase a commercial house with relatively good living conditions.

2) The commonality of urban Muslim migrants' living space distribution: The distribution pattern of "living around mosques and running business near mosques" still exists. The living space consists of points (mosques), lines (streets or traffic lines), and faces (aggregated areas) constitutes a spatial distribution pattern of the "mosa + community" residential circle. Differences: The Muslim migrants in Huifang, Xi'an, take the "Mosque-alley system" as an independent social organization form, and live in the space to present the "Mosque-alley Intertwined" distribution. The Muslim migrants in the village community in the outer city of Huifang have a "mosque" and a "farm market" as the dual-core, showing the "core (mosque/market) + community" inlaid living space situation. The Muslim migrants in Lanzhou generally adhere to "living around the mosque" or along the streets or roads that lead or pass through the mosque.

3) In terms of commonality, the living choices of Muslim migrants in both cities consider the distance from the place of work, the mosque or the Muslim community to the place of residence. In terms of differences, the choice of living mode of Muslim migrants in Xi'an is mainly influenced by the composition of living, wage income and occupational nature. The choice of residential location is mainly affected by the rent level, occupational nature and wage income of the house. However influencing factors include education level and housing rent level in Lanzhou city. The main influencing factors of residential location selection are education level and mobility purpose.

Based on the above conclusions, the following policy recommendations are proposed:

First, provide a diversified housing supply model according to local conditions. The Muslim migrants entering the city show that the housing search route is complicated, the quality of living is low, and the housing infrastructure is imperfect. Thus it is essential for the government to offer effectively guiding and $t$ multiple channels for the living choice of Muslim migrants in order to ease their economic payment and to provide them a diversified supply model in accordance with local conditions.

Secondly, improve the housing rental market. For Muslim migrants, renting is one of the best options for entering the city to solve the housing problem. The government should set a rental price that meets the criteria for renting houses and explore a living mode suitable for Muslim migrants. It is of great significance to promote the effective integration of Muslim migrants and residents.

Third, enhance the sense of belonging of Muslim migrants. Relevant departments and communities of the city government should actively listen to the opinions and suggestions of Muslim migrants, pay attention to the problems they face in urban life, improve their living environment, use various resources and policies to enhance their survival skills. Encouraging and assisting them to develop intra-ethnic mutual assistance and contact with other groups to increase their self-confidence and sense of belonging to the city.

The paper makes a comparative analysis of the living choice preferences, selection results and influencing factors of the Muslim migrants in Lanzhou and Xi'an, two representative cities in the northwest, and find some aspects that need to be perfected and worthy of further research:

1) The study illustrates the commonalities and differences in the choice of urban Muslim migrants from the aspects of residence, structure, location, etc. It is also necessary to consider the supply of urban infrastructure and public services for Muslim migrants so that the background information of residence choices is more comprehensive.

2) This study only used questionnaire data to analyze the living choices of urban Muslim migrants in a certain period, lacking a long-term follow-up survey. The results of the questionnaire reflect the process of choosing residence for some migrant Muslims, and it still need to be combined with the macro-residence pattern research based on the big data of urban floating population.

\section{Acknowledgement}

The work described in this paper was supported by the National Social Science Foundation of China (Grant No. 14BSH027) and by Belt and Road Special Project of Lanzhou University (Grant No. 20181dbryb008).

\section{References}

ÆrØ, T. (2006). Residential Choice from a Lifestyle Perspective. Housing, Theory and Society, 23(2), 109-130. https://doi.org/10.1080/14036090600773139

Ai, S. W. (2017). The Spatial Proximity Mechanism of Minority Commercial Economy: A Case Study of Mosque-Centered Agglomeration of Hui Traders in Kaifeng City. Economic Geography, 37(11), 127-135. (In Chinese)

Asiyanbola, A. R. (2006). Residential location decision-making and gender in Nigeria. Geoforum, 37(6), 1059-1065. 
https://doi.org/10.1016/j.geoforum.2006.01.006

Dieleman, F. M., \& Mulder, C. H. (2002). The Geography of Residential Choice, In: Residential Environments: Choice, Satisfaction and Behavior, 35-24.

Ding, J. H., Liu, Z. Y., Cheng, D. M., Liu, J., \& Zou, J. P. (2005). Areal differentiation of Inter-provincial Migration in China and Characteristics of the Flow Field. Journal of Geography, 60(1), 106-114. (In Chinese)

Fu, L., \& Tang, Z. L. (2008). The Social Special Structure of Floating Population in Shanghai and its Evolution Since the Reform and Opening-up. Urban Planning Forum, 1, 69-76. (In Chinese).

Gao, Y. J., \& Cao, A. J. (2012). Minority Population Flow: Drivers and Social Effects. Guangxi Ethnic Studies, 4, 163-169. (In Chinese).

Ge, J., \& Hokao, K. (2006). Research on residential lifestyles in Japanese cities from the viewpoints of residential preference, residential choice and residential satisfaction. Landscape \& Urban Planning, 78(3), 165-178. https://doi.org/10.1016/j.landurbplan.2005.07.004

Hao, X. N., Sun, J. Y., \& Bo, T. (2018).Study of the Effect of the Social Integration on Health among Floating People_ B Based on the Test of the Dynamic Monitoring Data of the National Floating Population in 2014. Population and Development, 24(4), 14-23. (In Chinese)

Hou, J. W. (2010). Beijing Floating Population Cluster: Trends, Models and Influencing Factors. Beijing: Guangming Daily Press. (In Chinese)

Hou, J. W. (2010). The Study on migrants agglomeration in Beijing: Current, Pattern and Determinants. Beijing: Guangming Daily Press. (In Chinese).

Hua, Q. (2011). The Research on the Development of Space of the Hui Enclave: A Case Study of Xi'an. Master Thesis, Xi'an University of Architecture and Technology, Xi'an, China. (In Chinese)

Jin, Z., \& Qiu, Y. H. (2009). Chinese religious report. Beijing: Social Science Academic Press. (In Chinese)

Le, A. T. (2008). Location, location, location: where do immigrants reside in Australia? Journal of International Migration and Integration, 9(4), 345-362. https://doi.org/10.1007/s12134-008-0070-z

Li, W. B. (2015). The Spatial Distribution and Influence Factors of Residential Rents of Central Districts in Xi'an City. Journal of Human Settlements in West China, 4, 77-81.

Liao, H. H., \& Gao, X. (2016). Study on the Living Preference of Floating Muslims in Lanzhou City during the Transition Period. Minzu Tribune, 7, 14-17. (In Chinese)

Lin, L. Y., \&Zhu, Y. (2008). The Living Status of the Floating Population in the Amphibious State and Its Constraints_— Taking Fujian Province as an Example. Population Research, 32(3), 48-56. (In Chinese)

Liu, T. T., Li, J. H., \& Gao, K. (2014). A Study of Housing Selection of the Floating Population with Family Migration and Its Influencing factors: A Case of Shanghai. South China Population, 29(3), 17-27. (In Chinese)

Liu, T., Chen, S. C., \& Cao, G. Z. (2019). Chinese Journal of Population Science. Chinese Journal of Population Science, 3, 80-91+127-128. (In Chinese)

Liu, Z. C. (2009). The analysis of Floating Population's living mode and Its Influence factors_— Taking Xi'an city as an example. Fujian Architecture \& Construction, 11, 25-27. (In Chinese)

Mao, F. F. (2009) A Research on the Housing Conditions and Inclinations of the Floating Population — a case study of the migrant workers in Hangzhou. Journal of Zhejiang gongshang University, 99(6), 90-95. (In Chinese)

Prashker, J., Shiftan, Y., \& Hershkovitch-Sarusi, P. (2008). Residential choice location, gender and the commute trip to work in Tel Aviv. Journal of Transport Geography, 16(5), 0-341. https://doi.org/10.1016/j.jtrangeo.2008.02.001

PRC. National Health Commission. (2019). Report on China's migrant population development. Beijing:China Population Publishing Company. (In Chinese).

Ren, Y. (2012). The Living Mode and Social Integration of Urban Floating Population. Shanghai: Sanlian Bookstore Press. (In Chinese)

Sha, Y. F. (2017). From "Living around Mosque" to "Inter-integrated Community"-Historical Changes of the Hui Community and Its Structure in the Northwest Ethnic Areas. Heilongjiang National Series, 6, 46-52. (In Chinese)

Shen, G. B., \& Qiu, M. H. (2008). Differentiation and Polarization of China's Urban Living Space in the Transformation Period. Journal of Shanghai University (Social Sciences Edition), 2, 148-154. (In Chinese) 
Shi, Z. L., \& Xue, W. L. (2014). Research on Housing Choice for Floating Population and Its Influential Factors_-Analysis of Dynamic. West Forum, 24(2), 25-33. (In Chinese)

Smith, B., \& Olaru, D. (2013). Lifecycle stages and residential location choice in the presence of latent preference heterogeneity. Environment \& Planning, 45(10), 2495-2514. https://doi.org/10.1068/a45490

Tan, Y. M. (2013). Research on residential spatial pattern and differentiation between different ethnic groups in Lanzhou city in transition. Master Thesis, Lanzhou University, Lanzhou, China. (In Chinese)

Tang, B. (2013). Analysis of the Factors Affecting the Living Space Pattern and the Choice of Residential Space of Urban Floating Population. Master Thesis, Fudan University, Shanghai, China. (In Chinese)

Tian, J. F., \& Li, W. L. (2018). A Study on the Comprehensive Evaluation of the Living Conditions of Urban Floating Population_— Taking Xi'an as an Example. Infrastructure Management Optimization, 30(1), 35-39. (In Chinese)

Wang, G. X. (2005). Distribution, Residence and Social Integration of Urban Migrant Workers: A Case Study of Shanghai. Population Research, 29(4), 39-41. (In Chinese).

Wu, X. (2003). Exploring the "Fringe Community"___Analysis of the Status Quo of the Floating Population in China. City Planning Review, 27(7), 40-45. (In Chinese)

Wu, X. (2010). Analysis of the Living Space of Floating Population in Big Cities of China—An Empirical Study for Migrant Workers. Nanjing, JS: Southeast University Press. (In Chinese).

Xiu, W. Y. (2015). The Study of Living Conditions about Floating Minority Population in Shanghai. Master Thesis, East China Normal University, Shanghai, China. (In Chinese)

Yang, W. J. (2013). The Change of Jamaat's Geography and Its Cultural Influence: A Case Study of the Hui Muslim Community in Lanzhou City. Journal of Hui Muslim Minority Studies, 2, 17-23. (In Chinese)

Yuan, Y., Xu, D. Q., \& Xue, D. S. (2007). Spatial Distribution, Evolution and Driving Force of Non-registered Population of Guangzhou Metropolitan Area in 1990-2000. Economic Geography, 27(2), 250-255. (In Chinese)

Zhang, F., \& Sun, L. (2010). Study on the Living Conditions of Floating Population in Big Cities_— Taking Beijing as an Example. Lanzhou Academic Journal, 7, 81-85. (In Chinese)

Zhang, S. Y., Shi, Z. Q., Song, X. Q., \& Deng, W. (2018). Space trade-offs analysis in the urban floating population residential self-selection: A case study of Chengdu. Geographical Research, 37(12), 2554-2566. (In Chinese)

Zhang, Y. (2012). An Empirical Study into Urban Social Adaptation about Migrant Muslims in Lanzhou City. Master Thesis, Lanzhou University, Lanzhou, China. (In Chinese)

Zhang, Z. B., \& Yang, Y. (2013). The Temporal and Spatial Changes of Muslim Population in Lanzhou City and Its Impact Mechanism. Chinese Journal of Population Science, 2, 89-100+128. (In Chinese) .

\section{Copyrights}

Copyright for this article is retained by the author(s), with first publication rights granted to the journal.

This is an open-access article distributed under the terms and conditions of the Creative Commons Attribution license which permits unrestricted use, distribution, and reproduction in any medium, provided the original work is properly cited. 